DOI: $10.17805 /$ zpu.2015.4.8

\title{
Брендинг как социальная система
}

\author{
Т. Л. БАГАЕВА
}

(КИЕВСКИЙ НАЦИОНАЛЬНЫЙ УНИВЕРСИТЕТ ИМ. Т. Г. ШЕВЧЕНКО, УКРАИНА)

Актуальное для отличающейся высокой степенью конкурентности, рискогенности и неопределенности современной брендинговой деятельности радикальное увеличение ее результативности предполагает прояснение и уточнение существующих - маркетинговых подходов к ее реализации. Решая эту задачу, автор приводит аргументацию в пользу того, что брендинговая деятельность формирует социальную систему, обладающую свойствами самореференции и саморазвития, сочетающую упорядоченность, заданную управляющим субъектом, с хаотическими, намеренными или спонтанными действиями функционирующих в ней социальных акторов. При этом необходимым коррелятом самореферентных операций системы является окружающий мир.

Так же как и брендингу, системный характер присущ функционированию отдельных брендов и их комплексов. При часто возникающей путанице в различении понятий “система бренда», “система брендов» и «система брендинга» автор предлагает трактовать их, соответственно, как коммуникационную, организационную и социальную системы.

В данной триаде система брендинга формируется и функционирует в конкурентном поле по инициативе социального актора - инициатора продвижения бренда, чему могут способствовать или препятствовать (умышленно либо спонтанно) входящие в данную систему другие социальные акторы, даже те, которые входят в собственную (внутреннюю) структуру инициатора продвижения бренда. Выделив функциональные узлы системы и стоящих за ними социальных акторов, можно предвидеть и выявить эмерджентные инфекции, а также точки бифуркации и осуществлять информационное и социальное воздействие на данных акторов с целью обеспечения структурной стабильности или оптимизации функционирования системы. Вместе с тем отклик системы на возмущение часто оказывается противоположным тому, что предсказывает интуиция.

Анализ брендинга, осуществленный автором на основе ряда современных социологических теорий, предопределяет уход от традиционного видения управления брендинговой деятельностью, принятого в маркетинге, и обосновывает новую концепцию брендинга как системы социального управления, сочетающего линейный и нелинейный контуры. 
Ключевые слова: бренд; брендинг; система бренда; система брендинга; социальный актор; социальное действие; самореферентность; самоорганизация

\section{BВЕАЕНИЕ}

$\Phi$ ункционирование и отдельных брендов, и их комплексов, и брендинга имеет системный характер. В каждом из этих трех случаев мы убеждаемся в наличии относительно независимого от среды и других аналогичных систем целостного объекта, состоящего из находящихся во взаимных отношениях элементов, представляющих собой неразложимые далее компоненты сложных объектов, явлений, процессов, которые формируют структуру (Керимов, 1998), фиксирующую относительно устойчивые связи между ними.

Чтобы избежать часто возникающей путаницы в процессе рефлексии в отношении бренда и брендинга, перед тем как осуществить анализ системы брендинга, видится целесообразным отграничить ее от системы бренда и системы брендов, что является целью данной статьи.

\section{ОПРЕАЕАЕНИЕ ПОНЯТИЙ}

Система бренда - коммуникативная система, представляющая собой комплекс взаимосвязанных факторов, формирующих восприятие сообщений о бренде. Наиболее удачной схемой, системно представляющей такие факторы, в наибольшей степени влияющие на коммуникативный потенциал системы бренда, видится так называемое колесо Bates, разработанное транснациональной коммуникационной компанией Bates (Рожков, Кисмерешкин, 2013: 102).

К этой системе применимы следующие трактовки.

Суть бренда (brand essence) - свойства бренда, качество, идея, воплощенные «ноу-хау». Аанные показатели, как правило, являются основополагающими, предопределяющими отношение к бренду целевой аудитории. Если он реально решает ее социальные проблемы, то имеет предпосылки стать лидером в ряду конкурентов.

Индивидуальность бренда (brand identity) - уникальные технологические и творческие решения в представлении бренда индивидам, которые позволяют им его персонализировать, отличать, наделять теми или иными чертами, выделять положительные особенности, отвечающие тем или иным социальным потребностям.

Ценности бренда (brand values) формируются совокупным усиленным воздействием вышеупомянутых факторов и, обладая определенной силой притяжения, предопределяют отношение к нему. Основная ценность бренда для индивида определяется соответствием его жизненным устремлениям.

Преимущества бренда (brand advantages) могут быть реальными или мифологизированными, но они всегда должны быть сформированными в параметрах интересов индИвИдОв.

Атрибуты бренда (brand attributes) - вызывающие функциональные или эмоциональные ассоциации особые черты, специфические элементы идентификации бренда - физические и потребительные особенности, формальные признаки отличия при его рекламном представлении с использованием каналов коммуникации.

В результате формируется образ, представляющий собой предпочитаемую инАивидом комбинацию разнообразной информации, которую он соотносит с представлениями о самом себе (self image). Если она уникальна и удовлетворяет его актуализировавшимся ожиданиям, бренд приобретает ауру высокой репутации, из- 
вестности, престижности, предпочтительности, добавляющих ему дополнительную ценность.

Система брендов - организационная система. Она представляет собой возглавляемый «родительским» (например, корпоративным) брендом иерархизированный комплекс, в котором каждый бренд предназначен специфической аудитории, с которой он коммуницирует. Например, в Ford Motor Co наименование Ford является родительским брендом, но одновременно оно присутствует для идентификации принадлежности к компании в наименованиях ее подразделений (сервисных, кредитных и др.), специализирующихся на выпуске грузовых или легковых автомобилей, маркирует их модификации (Ford Excort, Ford Taurus, Ford Focus и др.) и т. д.

Примерами систем брендов могут служить их комплексы, в которых каждый бренд имеет собственное имя, имидж, визуальные и вербальные особенности представления общественной среде, в то время как материнская компания остается для нее практически анонимной (в частности, Procter \& Gamble, имеющая сотни брендов - Tide, Pampers, Ivory, Pantene и др.); варианты расширения, в которых каждый из брендов носит «материнское имя» (зонтичный бренд) и в их рекламе используются узнаваемые образы и стилистика (например, компания Virgin, продвигающая под одной маркой Virgin бренды Virgin Megastore, Virgin Atlantic, Virgin Brides и др.); представляющие модификации продвигаемого объекта; варианты, в которых бренды находятся в процессе кооперации (ко-брендинга), например McDonald's и Coca-Cola.

Система брендинга - соииальная система, так как ее элементы представляют коммуницирующие между собой обладающие собственными целями, интенциями и возможностями самостоятельных действий индивиды, группы, общности, находящиеся во взаимодействиях и отношениях, образующие единое целое и поэтому обладающие функциями социальной системы.

\section{ОБОСНОВАНИЕ ТРАКТОВКИ ПОНЯТИЯ «СИСТЕМА БРЕНАИНГА »}

Аанное утверждение соответствует взглядам на такого рода системы, сформулированные в работах М. Вебера, Т. Парсонса, Р. Мертона. Брендинг должен рассматриваться в качестве именно системы, поскольку он представляет собой «целостный объект, состоящий из элементов, находящихся во взаимных отношениях», формирующих ее структуру (Керимов, 1998: 788).

Аанная система является социальной, так как это система мотивированного действия, организованная вокруг отношений социальных акторов друг к другу (Парсонс, Шилз, Олдс, 2002: 460-461). Если ее рассматривать через призму метода структурнофункционального анализа, предложенного Т. Парсонсом в развитие теории социального действия М. Вебера, становится очевидным, что акторы брендингового процесса, совершая социальные действия, согласно Веберу: целерациональные, ценностнорациональные, аффективные или традиционные (Вебер, 1990: 628), в определенной ситуации, при ориентации данных акторов на очевидные или мнимые их последствия, способствуют либо препятствуют продвижению и усилению бренда.

Под воздействием тех или иных мотивов эти акторы зачастую реализуют личные цели, используя имеющиеся в их распоряжении средства для их достижения, подчиняясь при этом принятым в системе нормам либо нарушая их.

Парсонс справедливо полагал, что нужно задать набор функций, которые отвечают за целостность и жизнеспособность объекта (Парсонс, 2002), в нашем случае - системы брендинга. Выделив те ее части и стоящих за ними социальных акторов, кото- 
рые выполняют именно эти функции, можно предвидеть эмерджентные инфекции, которые следует выявлять и на которые можно воздействовать для достижения результатов, желательных для инициатора брендингового процесса.

Нежелательным, в том числе деструктивным, процессам в системе брендинга противодействует модель ее «сохранения», так как большинству социальных акторов, функционирующим в этой системе, свойственно латентно воспринимаемое значение интеграции, инстинкт защиты культуры (в нашем случае - корпоративной культуры, соответствия идеологии и концептуального представления бренда), что на поведенческом уровне проявляется в регулировании энергетических напряжений путем их блокирования и канализации - направления в полезное русло.

Согласно Парсонсу, социальная система должна структурироваться с точки зрения важных для ее существования функций: адаптащии (в системе брендинга это приспособляемость к воздействию внешних и внутренних факторов, борьба с рассогласованиями); иеледостижения и снятия напряжений (способствования продвижению в целевые аудитории, усилению бренда); воспроизводства структуры (непрерывности и возобновляемости брендингового процесса), интегращии системы ( «оркестровки» брендингового процесса - термин, введенный транснациональной рекламнокоммуникационной корпорацией Ogilvy \& Mather, достижения лояльности социальных акторов его идеологии и практике) (Парсонс, 2002: 565-571). Этот набор функций отражается и в конфигурации социальных ролей, и в культурных нормативах, и в ориентациях социальных акторов как действующих лиц данного процесса.

Опишем систему брендинга, взяв за основу ее представление, распространенное в маркетинге, но акцентируя внимание на социальных аспектах.

Бренд формируется и функционирует в конкурентном поле по инициативе социального актора - иничиатора продвижения бренда, стремящегося его внедрить, поддержать, усилить его влияние на целевую аудиторию (на отдельных индивидов, их группы или общественную среду) путем включения в данную деятельность других социальных акторов, являющихся элементами системы. При этом воздействию бренда могут способствовать или препятствовать (умышленно либо спонтанно) даже те из них, которые входят в собственную (внутреннюю) структуру инициатора продвижения бренда.

Создание и реализация бренда - прерогатива организации, выполняющей посреднические функции (обычно коммуникационного агентства). Важно отметить, что упомянутая организация не подвержена воздействию продвигаемого бренда, так как является промежуточным - техническим звеном в его коммуникации с представителями целевой аудитории.

В систему брендинга входят еще и социальные акторы, представляющие элементы проводящей сети - подсистемы, участвующей в продвижении бренда (агенты, работники мест, где осуществляется контакт бренда с представителями целевой аудитории, и т. А.). Результативности кампании также способствуют или препятствуют ее протагонисты, конкуренты, лоббисты, СМИ, регулирующие органы, заинтересованные организации.

Чем мощнее коммуникативное воздействие бренда на целевую аудиторию и другие элементы системы брендинга, тем сильнее их реакция на это воздействие. В результате благодаря обратной связи инициатор продвижения бренда получает возможность осуществлять мониторинг такой реакции, позволяющий вычленить индикаторы результативности и правильности коммуникативных действий, оптимизировать их. 
На успех или неуспех брендинга, функционирующего в конкурентном пространстве, существенное влияние оказывает его экология - социальные, демографические, политические, культурные факторы. Взаимодействуя с внешней средой, система брендинга способна изменить отношения своих элементов, а значит - свою структуру, представляющую сеть упорядоченных и взаимообусловленных связей между ними.

Еще важно отметить, что система брендинга является диссипативной, т. е., по определению И. Пригожина и И.Стенгерса, характеризуется рассеянием вещества, энергии, информации (Пригожин, Стенгерс, 1986: 197). Аанная система сочетает порядок с хаосом - открытость, неравновесность (в нашем случае элементы системы брендинга), нелинейность (в нашем случае обмен информацией), сложность внутренней структуры, разнообразие форм проявления ее элементов и способность адаптации к внешней среде.

И. Пригожин и И. Стенгерс отмечали, что «очень часто откдик системы на возмущение оказывается противоположным тому, что подсказывает нам наша интуиция. Наше состояние обманутых ожиданий в этой ситуации хорошо отражает введенный в Массачусетском технологическом институте термин “контринтуитивный”... $<\ldots>$... единственной специфической особенностью сложных систем является то, что наше знание о них ограниченно и неопределенность со временем возрастает» (там же: 266, 305). Особо отметим, что создатели теории диссипативных систем справедливо обращали внимание на то, что «теорию структурной устойчивости интересно применить к проблемам социальной и культурной эволюции» (Николис, Пригожин, 1979: 488), следовательно, и к системе брендинга.

Открытость системы брендинга предопределяется тем, что она подвержена влиянию ее экологии, прежде всего социальной экологии, отношения с которой осуществляются в соответствии со схемой «входа/выхода» структуры и понимаются как правила трансформации (Иуман, 2007: 31-32). В брендинге - это стремление максимально сохранить статус-кво его системы путем «реформирования», планирования, менеджмента и контроля.

Система брендинга является самореферентной и самоорганизующейся. Согласно Н. Ауману социальные системы должны, по меньшей мере, быть способными внутрисистемно использовать различные системы окружающего мира как ориентацию и принцип производства информации. Поэтому самореферентная закрытость возможна лишь в экологических условиях. Окружающий мир является необходимым коррелятом самореферентных операций, потому что как раз эти операции не могут совершаться в случае солипсизма. Самореферентные системы обладают способностью устанавливать отношения с собой и дифференцировать их от отношений с окружающим миром.

Рефлексивные отношения такого рода не только революционизируют классическую эпистемологию, но и обеспечивают более комплексное понимание объекта (в нашем случае системы брендинга). Приложение социологической теории к рассмотрению системы брендинга в различных эпистемах позволит обнаружить и тематизировать латентные функции и эмерджентные точки бифуркации.

Очевидно, что управление такой системой, опираясь на традиционные приемы маркетинга, недостаточно продуктивно. Видится целесообразным опять обратиться к Н. Ауману, наследовавшему и осовременившему теоретические разработки Т. Парсонса и создавшему стройную теорию социальной системы. $\Lambda$ уман писал: «...возникают такие “синдромы теории”, как теория действия, теория систем, интеракционизм, 
теория коммуникации, структурализм, диалектический материализм... <... ...новое можно ожидать от комбинаций» (Иуман, 2007: 16). Вместо вопроса «Что такое общество?» Ауман ставит вопросы: «Как оно функционирует?», «Какие механизмы обеспечивают его постоянное воспроизводство?» и утверждает: общество - это всеобъемлющая система социальных коммуникаций (там же: 531).

Мы полагаем корректным поставить данные вопросы в процессе исследования системы брендинга, которая нам видится именно как «общество»- формирующая элементы системы группа людей, связанных друг с другом постоянными отношениями, общей географической или социальной территорией, подчиняющаяся утверждаемой инициатором продвижения бренда единой власти и доминирующей культуре либо им противодействующая. Согласно определению, приведенному в «Современном философском словаре» 1998 г., общество характеризуется как «сумма связей, совокупность или система отношений, возникающих из совместной жизни людей, воспроизводимых и трансформируемых их деятельностью» (Кемеров, 1998: 595). Социальные отношения между субъектами (акторами) в системе брендинга могут быть описаны как совокупность таких отношений между ними. Основой исследования данной системы, в частности, могут стать адаптированные к его специфике проблемные положения системного анализа, предложенные Ауманом, которые можно наложить на проблемы брендинга. Ауман указывает на существование предпочтительных связей, не отвергая других возможностей комбинаций (Ауман, 2007: 20).

Есть все основания соотнести с проблемами брендинга упомянутые проблемные положения системного анализа, предложенного Ауманом: различие системь и окружаюшего мира; системную дифференииачию; постоянное воздействие во всех явлениях системь и окружаюшего мира; отличие различия "система / окружаюший мир" от различия «элемент / отношения» (там же: 41-50), что приводит к наведенным или спонтанным эмерджентным изменениям как системы в целом, так и ее элементов); обусловливание отношений между элементами системь; комплексность; наличие гранич; единство многообразия; самореферениия (аутопойэсис); невозможность наблюдения самореферентной конституиии системь, если не придерживаться установленной ею прочессуальной и системной типизачии; расширение гранищь структурной приспособляемости благодарл различиям в самореферентньх системах, которье рассматриваются как информашия. Можно воздействовать на ее переработку, осуществлять контроль смещения структурной проблематики, исправлять ошибки, устранять разочарования, реагировать на причинные воздействия, вызывающие события, состояния, структурные изменения, непрерывности (там же: 74).

\section{ЗАКАЮЧЕНИЕ}

Взяв за основу вышеупомянутые положения, в процессе анализа брендинга как социальной системы мы можем выявить точки и векторы возможного информационного и социального воздействия на ее элементы и их связи. Таким образом, становится возможным уход от принятой в маркетинге традиционной практики управления в системе брендинга. Более того, возникает возможность представить новую концепцию, основанную на социальном управлении, сочетающем линейный и нелинейный контуры.

\section{СПИСОК АИТЕРАТУРЫ}

Вебер, М. (1990) Избранные произведения : пер. с нем. / сост., общ. ред. и послесл. Ю. Н. Аавыдова ; предисл. П. П. Гайденко. М. : Прогресс. 808 с. 
Кемеров, В. Е. (1998) Общество, социальное, социальность // Современный философский словарь / под общ. ред. В. Е. Кемерова. 2-е изд., испр. и доп. Аондон ; Франкфурт-на-Майне ; Париж ; Аюксембург ; М. ; Минск : Панпринт. 1064 с. С. 595.

Керимов, Т. Х. (1998) Система // Современный философский словарь / под общ. ред. В. Е. Кемерова. 2-е изд., испр. и доп. Аондон ; Франкфурт-на-Майне ; Париж ; Аюксембург ; М. ; Минск : Панпринт. 1064 с. С. $788-790$.

Иуман, Н. (2007) Социальные системы. Очерк общей теории / пер. с нем. И. А. Газиева ; под ред. Н. А. Головина. СПб. : Наука. 643 с.

Николис, Г., Пригожин, И. (1979) Самоорганизация в неравновесных системах: От диссипативных структур к упорядоченности через флуктуации / пер. с англ. В. Ф. Пастушенко ; под ред. Ю. А. Чизмаджева. М. : Мир. 512 с.

Парсонс, Т. (2002) О социальных системах / под ред. В. Ф. Чесноковой, С. А. Белановского. М. : Академический проект. 832 с.

Парсонс, Т., Шилз, Э., Олдс, Аж. (2002) Ценности, мотивы и системы действия // Парсонс Т. О структуре социального действия / под общ. ред. В. Ф. Чесноковой, С. А. Белановского. М. : Академический проект. 880 с. С. 458-562.

Пригожин, И. И., Стенгерс, И. (1986) Порядок из хаоса: Новый диалог человека с природой : пер. с англ. / общ. ред. В. И. Аршинова, Ю. А. Климонтовича, Ю. В. Сачкова. М. : Прогресс. 432 с.

Рожков, И. Я., Кисмерешкин, В. Г. (2013) Брендинг. М. : Юрайт. 331 с.

Aата поступления: 9.09.2015 г.

BRANDING AS A SOCIAL SYSTEM

\section{T. L. BAKHAEVA}

(TARAS SHEVCHENKo NATIONAL UNIVERSITY OF KYIV, UKRAINE)

Contemporary branding can be characterized as operating in a highly competitive, risk generating and uncertain environment. A dramatic rise in efficiency would involve auditing and refining its current marketing implementations. To help achieve this task, we suggest that branding builds a selfreferential and self-developing social system which combines the order assigned to it by a managing subject with chaotic, intentional or spontaneous activities of the social actors that operate within the system. The outside world is thus a required correlative of the system's self-referent operation.

Particular brands and their clusters, as well as branding in general, function systemically. As the notions of 'brand system', 'system of brands' and 'branding system' are frequently confused, we suggest they should be construed as a communicative, managerial and social system respectively.

In this triad, branding system emerges and operates in the competitive field in accordance with the initiative of the social actor that forces the brand promotion. Other social actors within the system can assist or hinder this process (whether intentionally or spontaneously), even though they may belong to the inner core of brand promoters. By pinpointing the functional nodes within the system and revealing the social actors behind it, we can predict and diagnose emergent infections and bifurcation points, and in that way exert social and informational influence over these actors to ensure the system's stability or optimize its functioning. At the same time, the system's response to the disturbance is often opposite to what the intuition has been predicting.

Our analysis of branding is based on a number of contemporary theories in social science and thus abandons the traditional marketing approach to branding management. We offer a new theory of branding as a social management system that combines linear and non-li-near circuits.

Keywords: brand; branding; brand system; branding system; social actor; social action; self-referentiality; self-organization

\section{REFERENCES}

Weber, M. (1990) Izbrannye proizvedeniia [Selected works] : transl. from German / collect., ed. and afterword by Yu. N. Davydov ; foreword by P. P. Gaidenko. Moscow, Progress Publ. 808 p. (In Russ.). 
Kemerov, V. E. (1998) Obshchestvo, sotsial'noe, sotsial'nost' [Society, the social, sociality]. In: Sovremennyi filosofskii slovar' [Modern philosophical dictionary]/ ed. by V. E. Kemerov. 2nd edn., revised and enlarged. London ; Frankfurt-on-Main ; Paris ; Luxemburg ; Moscow ; Minsk, Panprint Publ. 1064 p. P. 595. (In Russ.).

Kerimov, T. Kh. (1998) Sistema [System]. In: Sovremennyi filosofskii slovar' [Modern philosophical dictionary]/ ed. by V. E. Kemerov. 2nd edn., revised and enlarged. London ; Frankfurt-onMain ; Paris ; Luxemburg ; Moscow ; Minsk, Panprint Publ. 1064 p. Pp. 788-790. (In Russ.).

Luhmann, N. (2007) Sotsial' nye sistemy. Ocherk obshchei teorii [Social systems. An essay on the general theory] / transl. from German by I. D. Gaziev ; ed. by N. A. Golovin. St. Petersburg, Nauka Publ. 643 p. (In Russ.).

Nicolis, G. and Prigogine, I. (1979) Samoorganizatsiia v neravnovesnykb sistemakb: ot dissipativnykb struktur $k$ uporiadochennosti cherez fluktuatsii [Self-organization in nonequilibrium systems: From dissipative structures to order through fluctuations] / transl. from English by V. F. Pastushenko ; ed. by Yu. A. Chizmadzhev. Moscow, Mir Publ. 512 p. (In Russ.).

Parsons, T. (2002) O sotsial' nykb sistemakb [The social system] / ed. by V. F. Ches-nokova and S. A. Belanovskii. Moscow, Akademicheskii proekt Publ. 832 p. (In Russ.).

Parsons, T., Shils, E. and Olds, D. (2002) Tsennosti, motivy $i$ sistemy deistviia [Values, motives and systems of action]. In: Parsons, T. O strukture sotsial'nogo deistviia [The structure of social action] / ed. by V. F. Chesnokova and S. A. Belanovskii. Moscow, Akade-micheskii proekt Publ. 880 p. Pp. 458-562. (In Russ.).

Prigogine, I. and Stengers, I. (1986) Poriadok iz khaosa: novyi dialog cheloveka s prirodoi [Order out of chaos: Man's new dialogue with nature]/ ed. by V. I. Arshinov, Yu. L. Klimontovich and Yu. V. Sachkov. Moscow, Progress Publ. 432 p. (In Russ.).

Rozhkov, I. Ya. and Kismereshkin, V. G. (2013) Brending [Branding]. Moscow, Iurait Publ. 331 p. (In Russ.).

Submission date: 9.09.2015.

Багаева Татьяна Иеонидовна - кандидат социологических наук, докторант кафедры отраслевой социологии Киевского государственного университета им. Т. Г. Шевченко. Адрес: 01601, Украина, г. Киев, ул. Владимирская, А. 64/13. Тел.: +38050 3522365. Эл. адрес: tbahaeva@ bsca.com.ua

Bakhaeva Tatyana Leonidovna, Candidate of Sociology, Doctoral Candidate, Depart-ment of Branch Sociology, Taras Shevchenko National University of Kyiv. Postal address: 64/13 Volodimirovska St., 01601 Kyiv, Ukraine. Tel .: +38050 3522365. E-mail: tbahaeva@bsca.com.ua 